\title{
Management of a Rare Pathology in Children it is Lipomyelomenengocele about Casis Report
}

\author{
Bouchenaki F ${ }^{1 *}$, Habchi N ${ }^{2}$, Boustil K ${ }^{1}$, Benachou S ${ }^{1}$, Bakhti $\mathrm{S}^{1}$ \\ ${ }^{1}$ Neurosurgery department, EHS ALI AIT IDIR \\ ${ }^{2}$ Chu Mustapha Bacha neurosurgery department
}

*Corresponding Author: Bouchenaki F, Neurosurgery department, EHS ALI AIT IDIR.

Received date: November 30, 2021; Accepted date: December 28, 2021; Published date: January 10, 2022

Citation: Bouchenaki F, Habchi N, Boustil K, Benachou S, Bakhti S. (2022). Management of Choroid Plexus Papillomas. J. Neuroscience and Neurological Surgery. 11(1); DOI:10.31579/2578-8868/222

Copyrights: (C) 2022 Bouchenaki F, This is an open-access article distributed under the terms of The Creative Commons Attribution License, which permits unrestricted use, distribution, and reproduction in any medium, provided the original author and source are credited

\begin{abstract}
The lipomyelomeningocele (LMMC) is a type of congenital occult spinal dysraphism consistent with the presence of lipomatous tissue adhering to the epinetic marrow, which falls through a defect of the vertical colon with the former meninges and the marrow under posture the skin.

LMMC is the cause of the most frequent congenital attache between the cadre of the syndrome of the attached cord and causes a neurological deterioration due to the compression of the medical bone and the root system which is superadded.

It is therefore about a girl from 6 years ago with a swelling located in the region of Lombardy after the birth of the size of a tangerine which has increased the size gradually with age.

He presented the interrogation of the signs of urinary incontinence and the fact that he confirmed that he left us to fellow therapists who sent him to us for support.

The local examination of the lumbosacral region revealed a single mass without other distinctive skin signs, spherical in shape, $12 \times 10 \mathrm{~cm}$, soft and fixed in consistency.

A medullary MRI with effect, which reveals a mass of lipomate consistency at the level of lumbosacral associated with a bone spina extending from L5 to S2.

Surgical treatment was indicated as the patient had urinary problems. There were no postoperative complications and after a few months postoperative symptoms improved.

Keywords: lipomyelomeningocele; attached lower marrow; occult spinal dysraphism; sphincter incontinence
\end{abstract}

\section{Introduction}

Lipomyelomeningocele (LMMC) is a type of congenital occult spinal dysraphia consisting of the presence of lipomatous tissue attached to the spinal cord, which protrudes through a defect in the spine and meninges and spinal cord to form a posterior swelling under the skin which increases in size with age.

The neural ectoderm separates from the cutaneous ectoderm and the periaxial mesoderm enters intact with the unfused ventral neural ectoderm. The mesoderm then differentiates into adipose tissue, preventing the fusion of the neural canal and the posterior surface of the spine. [1]

CMMLs are lipomas that are tightly attached to the dorsal surface of a neural placode in the case of the dorsal variety and extend dorsally through spina bifida to be continuous with subcutaneous fat.

The lipoma is located immediately outside the connective tissue in the extradural space.

The rate of CMML has been estimated at 2.5 per 10,000 births.

There is a slight predominance of women in the literature review.

Patients usually present before the age of six months, but sometimes the disease goes unnoticed in childhood.

LMMCs are generally found subcutaneously in the lumbosacral region; they can behave benign causing no neurological problem has remained asymptomatic and therefore presented only an aesthetic problem but can sometimes cause symptoms of compression of neighboring structures through a bone defect. $[2,3,4]$ 


\section{Patients and methods}

A 6-year-old male patient weighing $25 \mathrm{~kg}$ presented with a lipoma in the lumbosacral region which gradually increased in size from birth.

He presented signs of urinary incontinence by the persistence of nocturnal enuresis which gradually became diurnal since the age of 3 years and the installation of fecal incontinence around the age of 4 years. and a half according to the statements of the parents who were confirmed by the pediatrician who referred him to us for surgical treatment.
The child's development was normal for his age and he did not present any orthopedic deformity in the lower limbs, only the existence of a bone spina in the lumbar region.

There were no complaints of back pain or leg pain.

The vaccine history was satisfactory.

Local examination of the lumbosacral region revealed a single mass without redness on the left paramedian, spherical in shape, $18 \times 14 \mathrm{~cm}$, soft and fixed in consistency.

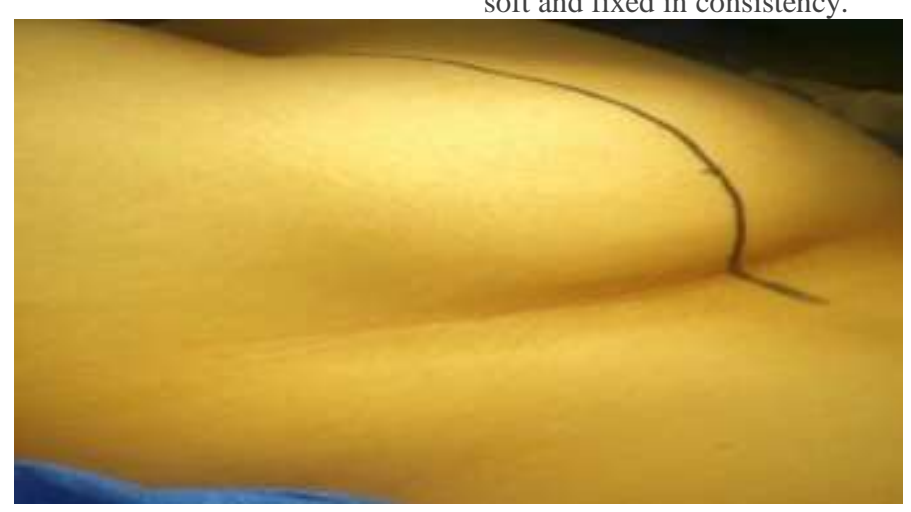

Figure 1: appearance of the lipomyelomeningocele

-The motor and sensory examination was normal.

The rectal examination revealed a decrease in the tone of the anal sphincter associated with urinary incontinence, the reason for his consultation with us.

According to the laboratory results, the blood count remains within normal limits and the ECB in the urine showed a confirmed infection which we treated beforehand.
In addition, he presented on the ultrasound of the urinary tract a dilation of the pyelocaliciel tracts already testifying to the repercussions of these disorders on the upper apparatus.

The patient has already performed a medullary MRI of the lumbosacral spine which revealed a mass of fat density at the lumbosacral level adhering to the dorsal surface and involving the cone which connected through a bone defect located at the level of the sacred region from L5 to S2.
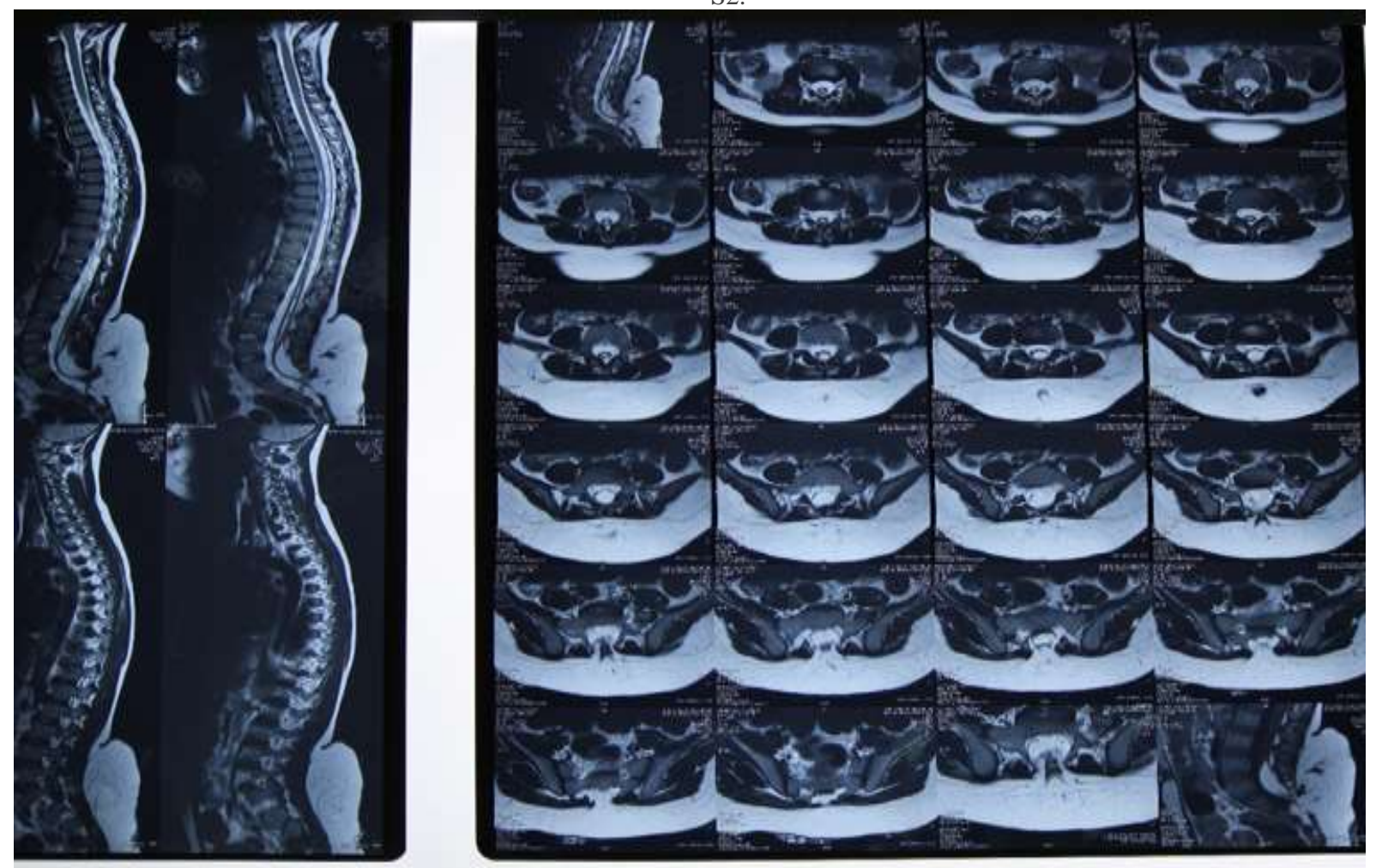

Figure 2: Sagittal and axial sections showing a lipomyelomeningocele of the caudal variety with syringomyelic cavity. 

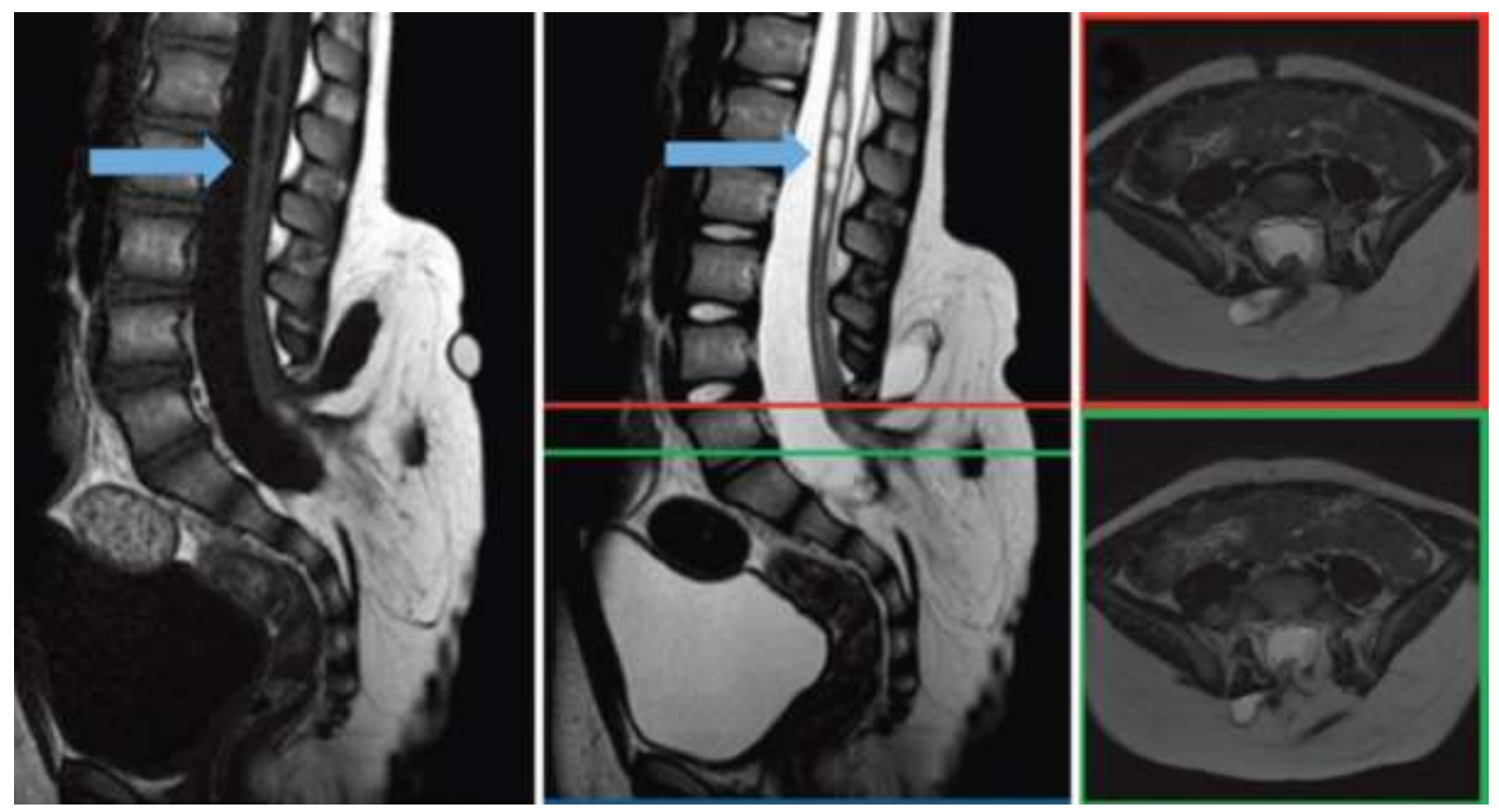

Figure 3: Blue arrow presence of a syringomyelic cleft accompanying the lipoma of the caudal variety

The patient was operated on under general anesthesia in the prone position.

We made a vertical incision centered on the lipomatous mass of L4-S2.

The excision of the latter was carried out using the ultra sonic vacuum cleaner until the dura mater as well as the spinal cord which was located outside the dura mater, which we freed from the dura mater, was revealed. any lipomatous attachment and fibrous adhesions with the help of the ultrasonic aspirator and under the control of a nerve stimulator ; the section of the filum was the last stage of our intervention.

The dural closure was done by an enlargement plasty.

\section{Discussion}

CMML is the most common cause of congenital attachment (attached spinal cord syndrome "SMA") and causes neurological deterioration due to compression of the spinal cord and radicular ischemia. [1.5]

The pathogenesis of clinical ADS syndrome is believed to arise from traction on the lower end of the spinal cord by a thick terminal filum.

Traction on the medullary cone then results in decreased blood flow and decreased oxidative metabolism, which can eventually cause the symptoms and clinical signs of ADS.

Its clinical features include neurologic, orthopedic, and urologic abnormalities which may be improved upon removal of the lipoma and detachment of the filum terminale.

There are several corollaries to the ischemic hypothesis in ADS.

The first is that the mechanical properties of the ponytail are important, so that a thicker terminal filum or with fatty infiltration causes higher tension.

Second, these mechanical properties prevent normal migration of the spinal cord, which exacerbates this traction. [5]

The most common presenting symptom is a fat mass positioned on the midline or paramedian line in the lumbosacral region.
In addition, in the majority of cases they present skin lesions associated with the lipoma, in particular skin hemangiomas, skin dimples and a hairy nevus among others.

Other symptoms mainly related to traction on the spinal cord include motor deficits, tone disturbances such as spasticity, sensory disturbances involving one or more root paths, urodynamic and / or urorectal dysfunctions and secondary orthopedic deformities.

Symptoms are progressive if left untreated. [4,5,6]

A series of 80 patients reported by Kanev et al. [7] have shown that bowel and bladder function deteriorates before motor function on physical examination.

The progression of the disease can lead to frequent urinary tract infections ; incontinence or even episodes of retention can be seen as well as intestinal disorders can appear such as neurogenic constipation until reaching the final stage of incontinence.

The urinary disorders in these children are secondary to an alteration of the innervation of the urinary system, either by malformation during embryogenesis or by a marrow attached by CMML.

Urinary dysfunction may be due to detrusor paresis, external sphincter dysfunction, or most commonly detrusor sphincter dyssynergy.

Urinary dysfunction can cause symptoms such as urinary incontinence, frequent urinary tract infections, urgent urination, and in severe cases of urological dysfunction hydronephrosis or pyelonephritis can cause damage to the upper urinary tract.

The initial symptom of a neurogenic bladder is frequently a change in the urination pattern.

Urodynamic tests to assess urologic dysfunction can help assess the severity of the dysfunction.

In addition, an abnormality of bladder function may be the only evidence of neurological damage in these children. [6] 
Orthopedic deformities may accompany the picture such as limb shortening, foot deformities, gait abnormalities, scoliosis, spasticity, and back and leg pain.

Three categories of CMML exist, based on the relative anatomy of the lipoma and neural components: dorsal, transitional, and caudal.

Dorsal-type lipomas have an area of attachment to the dorsal spinal cord at the level of myeloschisis in the lower lumbar or lumbosacral levels of the spinal cord and are continuous with the subcutaneous tissue.

The lipoma passes through a fascial defect and may extend and involve the central canal.

A dural defect is present and the placode-lipoma interface may be located in the extradural space.
Caudal -type lipomas arise mainly from the caudal end of the medullary cone.

These lipomas can spread through a dural defect or can be enclosed in the dura. [5.6]

Transition lipomas have a tether that extends beyond the area of myeloschisis to the cone, with a less distinct lipoma-marrow interface.

The lipoma again spreads through a dural defect.

In addition, Pang et al. [8] Describes a chaotic type, which has an irregular border between the placodes and lipoma. The fat extends around the spinal cord and on its ventral surface.

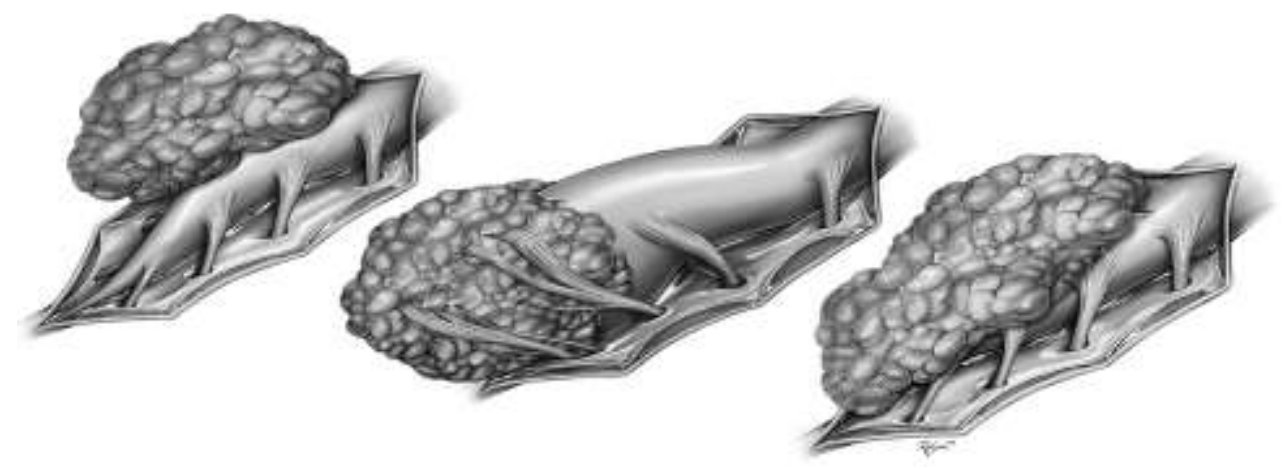

Figure 4: Classification of cone medullary lipomas according to Chapman. 3 varieties: Dorsal, caudal, transitional from left to right.

Because the natural progression of CMMLs causes neurologic deficits and / or urologic disturbances, prophylactic surgery is recommended for these lesions by some authors. [2]

-The objectives of the surgery are four in number:

a / Excision of the fibro-adipose mass, b / To relieve the effect of attachment on the spinal cord,

c / To preserve the nervous tissues

$\mathrm{d} /$ And to prevent the attachment of the spinal cord.

The basic surgical procedures are the same for each type of lipoma, but the degree of difficulty of the surgery is different for each type. [3].

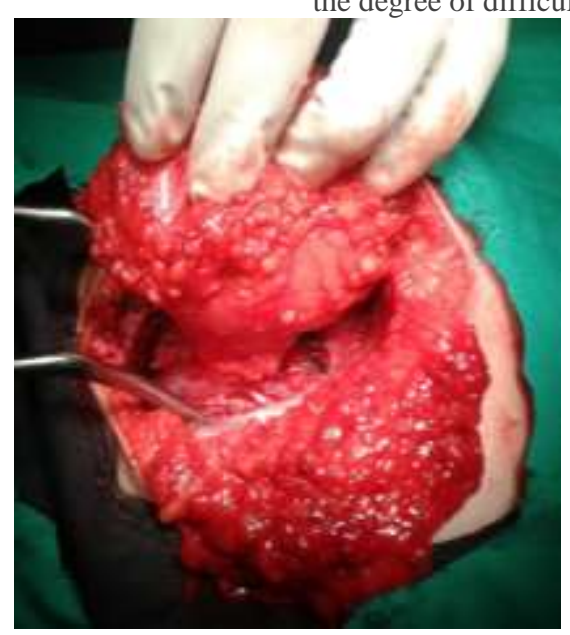

Figure 5: Release of the circumference of the LMMC 


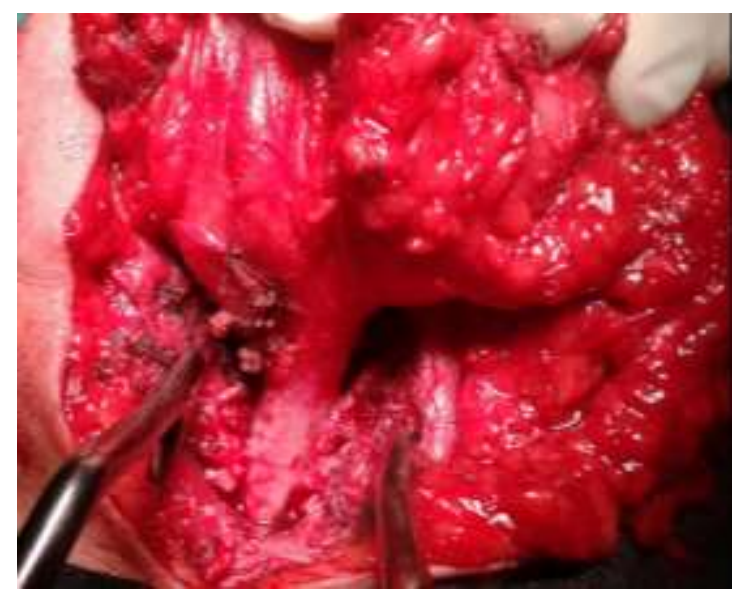

Figure 6: visualization of the lipomatous stem or lipomatous stalk

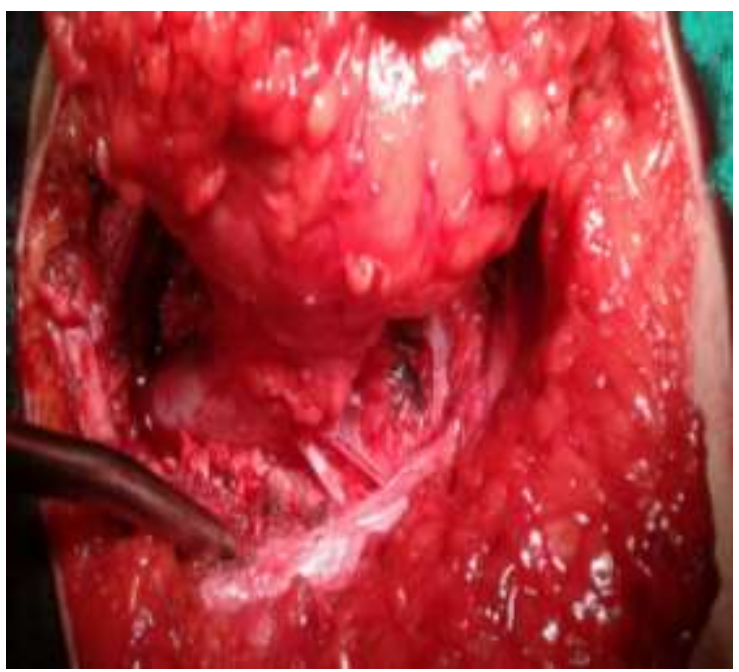

Figure 7: demonstration of the sacral roots and lipomatous stem

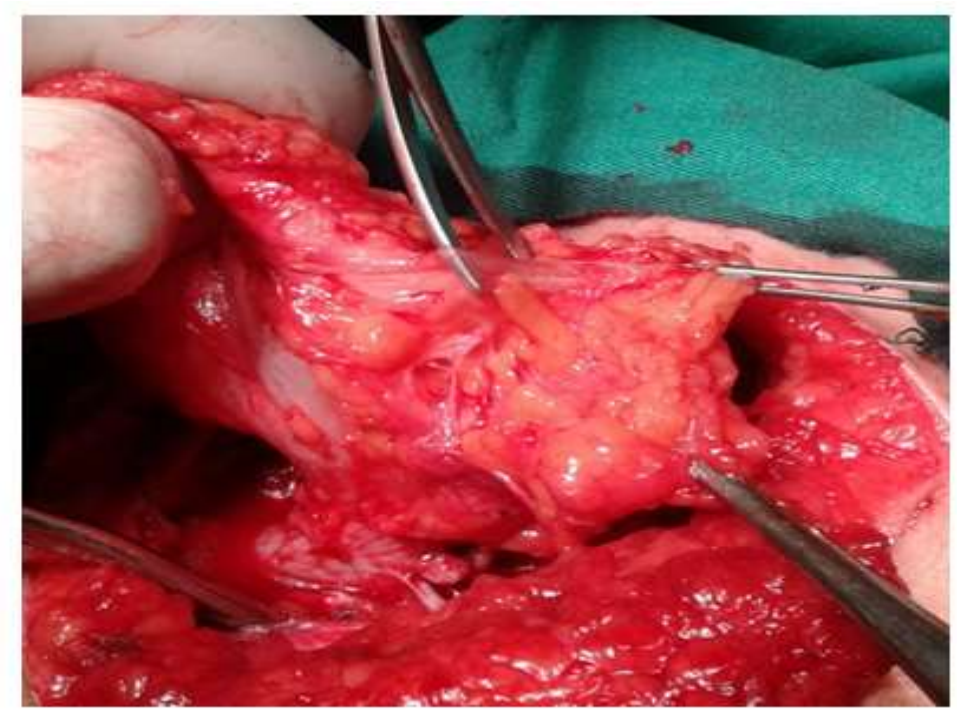

Figure 8: opening of the contents of the LMMC 


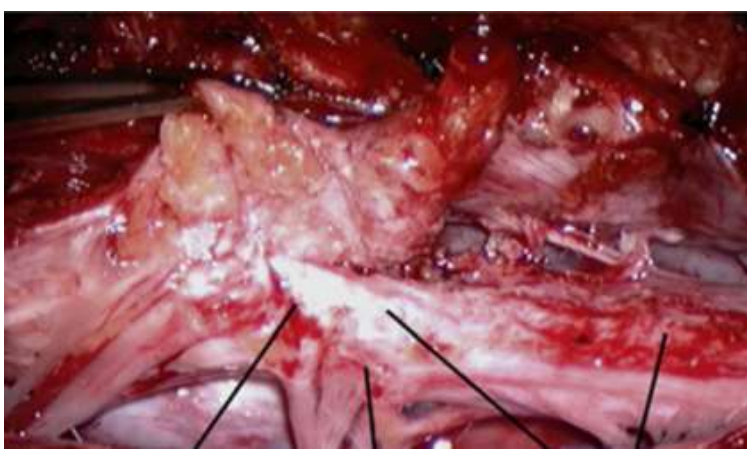

Figure 9: Release of the Placode from the Lipoma and exposed

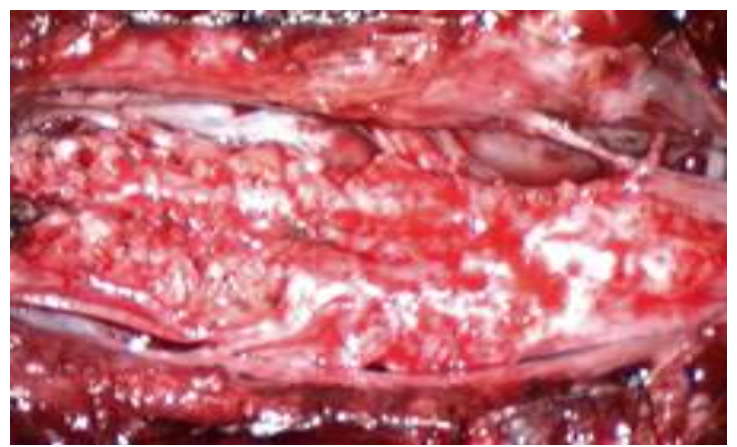

Figure 10: Neural Placode freed from any infiltrate from the lipomatous interface

\section{Conclusion}

The management of LMMC remains a challenge for the neurosurgeon. Should it be operated or wait for the symptoms to appear?

Patients with clearly progressive symptoms should be treated surgically in order to stop the progression in the worst case.

When the surgical management is chosen, the experts recommend an aggressive resection of the lipoma, as well as a reconstruction of the placodes and a large expandable duraplasty, the evolution of our patient in postoperative did not present any complications and the symptoms improved after a few months and after rehabilitation.

Prophylactic surgery can theoretically prevent the onset of neurological deterioration or stabilize and reverse early-onset symptoms at diagnosis, particularly in infants with large intradural lipoma and associated syrinx involving the prognosis. functional.

Early surgery can prevent the onset of ischemic phenomena of the medullary tissue and the complications of severe urological dysfunction; however, according to some authors, this has not shown that it offers immunity against other additional deterioration that may develop later.

\section{References:}

1. Gunkalar D, Gonal M. Cervical Lipomyelomeningocele: case illustration. Neurocirugía. 2007; 18: 505-507.

2. Erol SH, Ucler N, Yakar H. Lateral lower thoracic lipomyelomeningocele: a case report. Cases Journal 2009, 2: 8122.

3. Oakes W: Management of spinal cord lipomas and lipomyelomeningoceles, in Wilkins RH, Rengachary SS (eds): Neurosurgery Update II. New York: McGraw-Hill, 1991, Vol 3, pp3497-3504.

4. Shetty DS, Lakhkar BN. Lateral Sacral Lipomyelomeningocele: A Rare Anomaly. Neurol India, 2002; 50: 204-206.

5. Kang K, et al. Tethered Cord Syndrome; Surgical Indication, Technique and Outcome. J Korean Neurosurg Soc 42: 7782.2007.

6. Sarris SC, Krystal SB, Carmel PW, Lipomyelomeningocele: Pathology, Treatment, and Outcomes. Neurosurg Focus. 2012; 33 (4).

7. Kanev PM, Bierbrauer KS: Reflections on the natural history of lipomyelomeningocele. Pediatr Neurosurg 22: 137-140, 1995

8. Pang D (ed): Spinal cord lipomas, in: Disorders of the Pediatric Spine. New York: Raven Press, 1995, pp 175-201. 
(cc) (i)

This work is licensed under Creative

Commons Attribution 4.0 License

To Submit Your Article Click Here:

Submit Manuscript

DOI: $10.31579 / 2578-8868 / 221$
Ready to submit your research? Choose Auctores and benefit from:

$>$ fast, convenient online submission

$>$ rigorous peer review by experienced research in your field

$>$ rapid publication on acceptance

$>$ authors retain copyrights

$>$ unique DOI for all articles

$>$ immediate, unrestricted online access

At Auctores, research is always in progress.

Learn more https://auctoresonline.org/journals/neuroscience-and-neurologicalsurgery- 